\title{
Fault Transient Analysis and Protection Performance Evaluation within a Large-scale PV Power Plant
}

\author{
Jinghua Wen ${ }^{1}$, Meiling Luo ${ }^{1}$, Chenjie $\mathrm{Gu}^{2}$, Hongsheng Wei ${ }^{2}$ and Bohan $\mathrm{Liu}^{3}$ \\ ${ }^{1}$ State Grid Ningxia Electric Power Company, Ningxia, China \\ ${ }^{2}$ State Key Lab of Alternate Electrical Power System with Renewable Energy Sources, North China Electric Power University, \\ Beijing, 102206, China \\ ${ }^{3}$ State Grid AC Project Construction Co., Ltd, Beijing, China
}

\begin{abstract}
In this paper, a short-circuit test within a large-scale PV power plant with a total capacity of $850 \mathrm{MWp}$ is discussed. The fault currents supplied by the PV generation units are presented and analysed. According to the fault behaviour, the existing protection coordination principles within the plant are considered and their performances are evaluated. Moreover, these protections are examined in simulation platform under different operating situations. A simple measure with communication system is proposed to deal with the foreseeable problem about the current protection scheme in the PV power plant.
\end{abstract}

\section{Introduction}

The recent progress in renewable-energy (RE) technologies has led to the erection of RE power plants up to the order of several hundred megawatts [1]. According to the Global New Energy Development Report 2014, the world's photovoltaic market is shifting from Europe to Asia, with China becoming the largest market [2]. In China, the installed capacity of photovoltaic (PV) power plants currently accounts for over $80 \%$ of the total PV installed capacity. Such large PV power plants are naturally part of the transmission networks and hold non-negligible proportions of the generation. Consequently, the fault ride-through requirement (FRT) has become an essential part of modern grid codes [3].

As a result of the FRT schemes, the PV generators' impacts on protective relaying become challenging. Some researchers have studied the effect of fault on PV power plants, specially the inverters and have investigated measures in protecting the PV inverters [4,5]. However, an overall protection scheme has yet to come to solve the protection crisis in PV power plants.

Like distribution networks, where overcurrent protection based on the assumption of a single path for the fault current is predominant, the collection system in a PV power plant has a similar radial topology with overcurrent protection, but the terminals are PV generators instead of

This work was supported in part by the National Basic Research Program (973 Program) (2012CB215206), by the National Natural Science Foundation of China (NSFC) project under Grant 51407067, by Fundamental Research Funds for the Central Universities- FRFCU (2016ZZD01) loads. The relay coordination might be affected by the additional current paths which are introduced by the PV generators, or the protection system selectivity may be at risk because of bidirectional fault currents. Various researches on distribution networks relaying have be done and some effective remedies are offered. In [6], the issues are identified such as PV generators feeding faults after utility protection opens, PV generators feeding the faults on adjacent feeders, and reclosure coordination. [7] focused on the coordination loss. [8] investigated the loss of speed in protective devices, sympathetic tripping, and unintentional islanding. They have suggested the use of a communication system in order to address these issues. The adaptive relaying algorithm is adopted to automatically amend the protection settings in the presence of inverter-based distributed generations in $[9,10]$.

Different with distribution networks penetrated with DGs, the power from the PV generators flows to the substation under the normal condition. The fault behavior within the plant is necessary to be revealed and an overall protection scheme is in great need to help reduce the protection crisis in PV power plants.

The rest of this paper is arranged as follow. Section 2 presents a detailed description about the PV power plant. In Section 3, the fault currents recorded in the short-circuit test are analyzed. Based on the exposed fault behavior, Section 4 presents the existing protection configuration and the performance is evaluated. Section 5 summarizes the derived conclusion. 


\section{Field test scenario}

The PV power plant has a capacity of $850 \mathrm{MWp}$, with a $330 \mathrm{kV}$ substation comprising four main transformers. The partial topology in Fig. 1 involves two main transformers. Six overhead lines are connected into the $35 \mathrm{kV}$ side of each main transformer and the other end of each line is connected with a corresponding collection station bus. This sort of collection station has two buses and collects 64 PV generation units generally. A single PV generation unit has a capacity of $1 \mathrm{MWp}$ and includes two $500 \mathrm{~kW}$ voltage source converters (VSC), and a step-up transformer boosting the voltage up to the medium level.

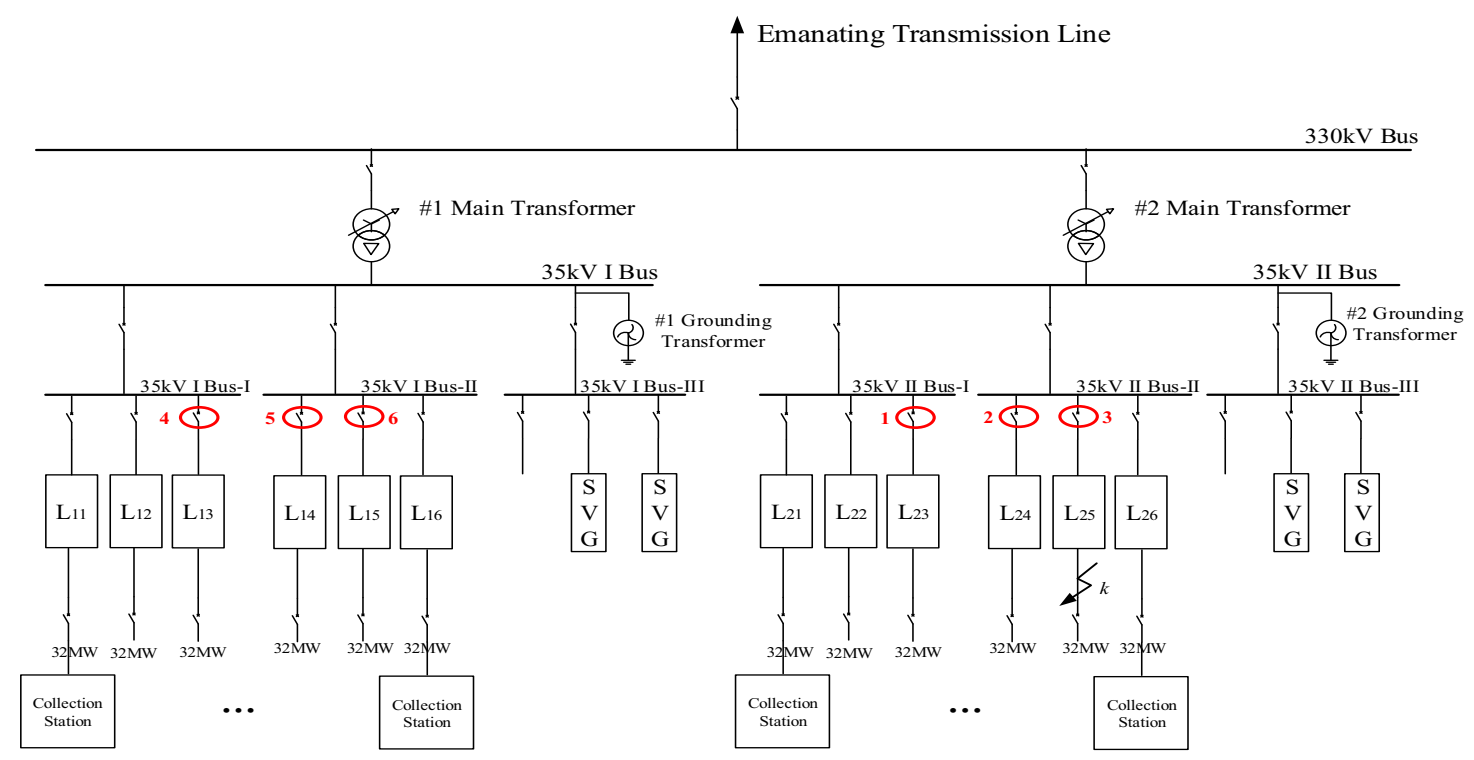

Figure 1. The partial topology of the PV power plant.

The details about the collection station and the PV generation unit will be described in Section 4. The remaining two main transformers are connected to the $330 \mathrm{kV}$ bus in parallel with \#1 and \#2 main transformers.

In the test, the fault was applied on the overhead line $\mathrm{L}_{25}$ close to the exit of the collection station, $k$ in Fig. 1 . At $8.86 \mathrm{~s}$, the phase $\mathrm{B}$ to ground (BG) fault occurred, and developed into $\mathrm{BC}$ to ground $(\mathrm{BCG})$ at $9.09 \mathrm{~s}$, and was isolated at $9.17 \mathrm{~s}$. It should be noted that \#2 grounding transformer and the SVGs did not work during the fault.

The PV power plant was not operating under the rated conditions for the local non-optimum weather. The power factor (PF) was almost unity one. Table 1 presents the prefault power delivered through certain overhead lines.

Table 1. Powers delivered through the overhead lines

\begin{tabular}{|c|c|c|c|}
\hline Overhead line & P(MW) & Q(MVar) & PF \\
\hline $\mathrm{L}_{13}$ & 22.9 & -0.83 & 0.999 \\
\hline $\mathrm{L}_{14}$ & 20.4 & -1.2 & 0.998 \\
\hline $\mathrm{L}_{15}$ & 18.8 & -1.0 & 0.998 \\
\hline $\mathrm{L}_{23}$ & 23.1 & -2.0 & 0.996 \\
\hline $\mathrm{L}_{24}$ & 18.3 & -0.1 & 1.000 \\
\hline $\mathrm{L}_{25}$ & 26.2 & -1.3 & 0.999 \\
\hline
\end{tabular}

\section{Fault currents analysis}

Measurement points are marked with the ovals in Fig. 1 and can be divided into two groups according to the electrical distance from the fault point. The measurement points on $\mathrm{L}_{23}, \mathrm{~L}_{24}, \mathrm{~L}_{25}$ near to the fault point are marked as $1,2,3$ sequentially, while the ones on $\mathrm{L}_{13}, \mathrm{~L}_{14}, \mathrm{~L}_{15}$ comparatively farther from the fault point are marked as 4 , 5,6 sequentially. In this section, the fault currents of typical measurement points are analyzed. In the frequency domain, the currents are analyzed with the method of moving window fast Fourier transformation (FFT). The window length is three cycles on a $50 \mathrm{~Hz}$ base and the step is one cycle. The first window is between $8.80 \mathrm{~s}$ and $8.86 \mathrm{~s}$.

\subsection{Measurement points 2}

During the BG fault, for the step-up transformers have ungrounded star primary and delta secondary, voltages at the secondary side do not detect the primary fault presence. So the current supplied by the PV systems are not affected by such primary single line-to-ground (SLG) fault as shown in Fig. 2.(b).

During the BCG fault, due to the overhead line impedance, the fault-phase voltages on $35 \mathrm{kV}$ Bus II are not equal to zero in Fig. 2.(a). The currents of $\mathrm{L}_{24}$ are symmetrical in Fig. 2.(b). The fundamental current of each phase increases to $0.68 \mathrm{pu}$ by about $17.2 \%$. The harmonics perform as odd ones and the third-order one accounts for approximately $4 \%$ of the fundamental, in Fig. 3.

\subsection{Measurement point 5}

During the BG fault, a SLG fault at primary side has no impacts on the voltages at the secondary side, for the wingding connection type of main transformers (YNd11). Therefore, the currents from corresponding PV systems are same to the prefault ones, as shown in Fig. 4.

During the BCG fault, the amplitude of the fault-phase voltages on $35 \mathrm{kV}$ Bus I decreases into about 
$0.85 \mathrm{pu}$ in Fig. 4.(a). At the fault inception, the instantaneous values of $I_{\mathrm{b}}$ and $I_{\mathrm{c}}$ increase to the maximum $0.784 \mathrm{pu}$ and $0.815 \mathrm{pu}$, respectively. During the steady state, $I_{\mathrm{a}}$ reaches the maximum $0.816 \mathrm{pu}$ and three-phase currents are substantially symmetrical, as shown in Fig. 4.(b). The fundamental current value of each phase is about $0.69 \mathrm{pu}$ except that $I_{\mathrm{a}}$ is $0.72 \mathrm{pu}$, about $12 \%$ larger than the prefault value. The harmonics mainly perform between $100 \mathrm{~Hz}$ and $150 \mathrm{~Hz}$ in Fig. 5 .

Through the analysis above, one can find that the fault currents contributed by PV systems are at low level and the instantaneous maximum value could even not reach the rated value, because the fault behavior is governed by the control system that determines the switching pulses of the grid-connected converter [11] and the operating point of PV arrays may deviate from maximum power point (MPP) during faults. The odd harmonic component is relevant to the inverter modulation under unbalanced faults [12]. The harmonics values are too low to have effects.

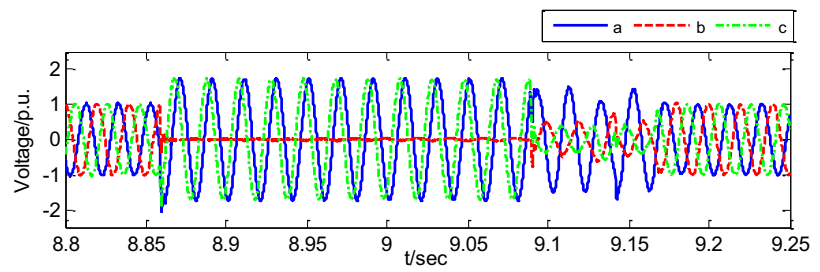

(a) Three-phase voltages on $35 \mathrm{kV}$ Bus II

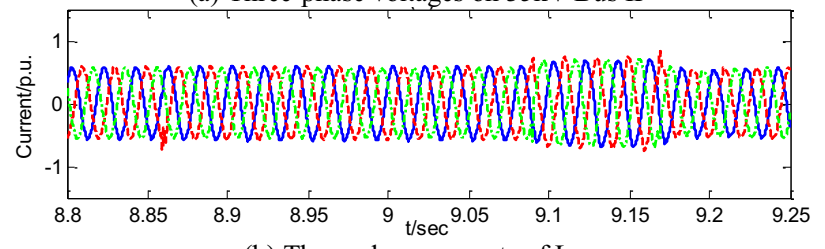

(b) Three-phase currents of $\mathrm{L}_{24}$

Figure 2. Voltages and currents recorded in the field test.

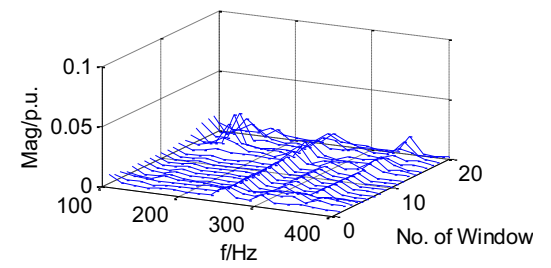

Figure 3. The current spectra in high band of the current of $L_{24}$.

\section{Protection Configuration Evaluation}

A collection station has two $35 \mathrm{kV}$ buses and each bus collects 4 branch cables and an overhead line is connected with each bus. $8 \mathrm{PV}$ generation units converge via a branch cable. An overhead line is configured with three sets of protection, the pilot current protection as the primary one, the overcurrent protection as the backup and the zero-sequence current protection for the grounded faults. The branch cable is equipped with two sets of protection, the overcurrent protection as the primary one and the zero-sequence current protection for the grounded faults. The specific coordination principles are displayed in Table 2.

\subsection{Pilot current protection}

The analysis in Section 3 indicates that the currents contributed by PV generation units increase not too much during faults. Considering that the system's short-circuit capacity is much greater, the short-circuit current from upstream will be much greater than the one from downstream. The ratio between the differential current and the braking current will be small so that the sensitivity will be reduced. Moreover, the PV power plant does not operate under the rated conditions for most time of the day, the sensitivity will be lower.

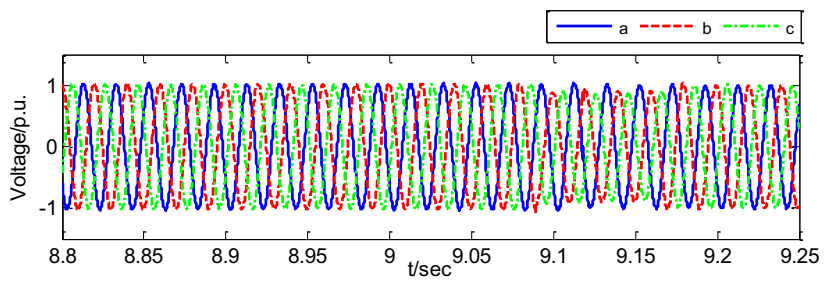

(a) Three-phase voltages on $35 \mathrm{kV}$ Bus I

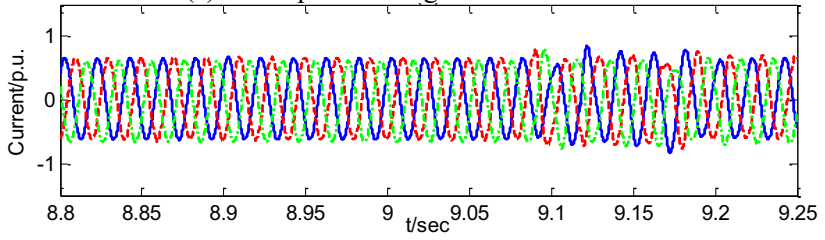

(b) Three-phase currents of $\mathrm{L}_{15}$

Figure 4. Voltages and currents recorded in the field test.

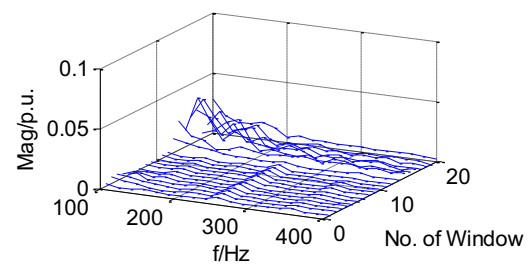

Figure 5. The current spectra in high band of the current of $\mathrm{L}_{14}$.

\subsection{Overcurrent protection}

Suppose that a fault occurs on a branch cable, the current through the relay on the faulty cable is supplied by the system, the adjacent overhead lines and the neighboring branches. The current value must be larger than the setting values of the overcurrent protection on a branch cable. At this time, the coordination among the stages of the branch cable and the overhead line is same to a traditional radical distribution network and then accurate operation can be assured. In addition, the relays of neighboring branches and adjacent overhead lines will not malfunction for the low-level fault currents supplied by PV systems.

Suppose that a fault occurs on an overhead line, the current from the upstream is supplied by the system and the adjacent overhead lines. For the first stage assuring the sensitivity of 2 in case faults at the collection station bus, the upstream short-circuit current will be much greater than setting values of the upstream overcurrent protection. On the other side, the current from the downstream is contributed by the corresponding PV generation units. The first-stage setting value is the 
upstream counterpart divided by 1.1. Obviously, the short-circuit current from downstream cannot reach this level. The second-stage setting value is $1.2 \times 6 I_{\mathrm{e}}$ and higher than the maximum fault current supplied by 4 branch cables and the third stage will not pick up because the output current of typical commercial PV inverter products are designed for below 1.2pu [13]. Similarly, the overcurrent of a branch cable will not pick up. So, this will result in the rejection of the downstream overcurrent protection.

Therefore, a fault on an overhead line will be isolated by the upstream protection with a time delay when the pilot protection is out of service. Unfortunately, the PV generation units being cut off will continue to contribute currents to the failure point. This could damage the components in the circuit and bring security risk to the maintenance personnel. Most seriously, this may result in asynchronous reclosure and cause stoke currents, and reclosure failure for the fault still supplied by the PV generation units. The stability and security of the system and the plant will be influenced.

\subsection{Zero-Sequence current protection}

For a SLG fault on a $35 \mathrm{kV}$ line has almost no effect on both the system and the PV generation units. But a SLG fault may lead to a worse fault, a SLG fault within the collection system must be isolated immediately in a PV power plant [14]. To detect a SLG fault and isolate the failure, the zero-sequence current protection is established with a grounding transformer.

The first and second stage at different locations have same setting values indicated by $I_{\mathrm{a}}$ and $I_{\mathrm{b}}$, respectively. The coordination is based on time intervals. Given step-up transformers with ungrounded primary and main transformers with delta secondary, in the event of earth faults, the zero-sequence circuit is composed of the distributed capacitance of overhead lines and branch cables, the zero-sequence impedance from the fault point to the grounding transformer, and that of the grounding transformer and its grounded resistance.

Suppose now that a SLG fault occurs on a branch cable, the time grading can ensure the shortest section should be disconnected.

Suppose now that a SLG fault occurs on an overhead line, the zero-sequence current flowing towards the downstream is only the capacitive current and it may not start the first stage. While that flowing towards the upstream is high enough to start the upstream first stage. The time intervals for the first stages at both ends are identical so that the upstream first stage will operate prior to the downstream one. Then, this case may result in the same risks as discussed in overcurrent protection.

Table 2. Existing protection coordination

\begin{tabular}{|c|c|c|c|c|c|}
\hline Location & \multicolumn{2}{|c|}{ Protection Type } & Coordination Principle & Setting Value & Delay \\
\hline \multirow{5}{*}{$\begin{array}{l}\text { Substation Side } \\
\text { (Upstream) }\end{array}$} & \multirow{3}{*}{ Overcurrent } & I & Sensitivity of 2 when a fault occurs at the end & $0.866 I_{\mathrm{f}(3)} / 2$ & $0.1 \mathrm{~s}$ \\
\hline & & II & Coordinate with next stage I & $1.2 * 6 I_{\mathrm{e}}$ & $0.6 \mathrm{~s}$ \\
\hline & & III & Maximum load current & $1.3 n I_{\mathrm{e}}$ & $0.9 \mathrm{~s}$ \\
\hline & \multirow{2}{*}{$\begin{array}{l}\text { Zero-sequence } \\
\text { Current }\end{array}$} & I & Grounding resistance limit current & $I_{\mathrm{a}}$ & $0.3 \mathrm{~s}$ \\
\hline & & II & Line capacitive current & $I_{\mathrm{b}}$ & $0.9 \mathrm{~s}$ \\
\hline \multirow{5}{*}{$\begin{array}{l}\text { Collection } \\
\text { Station Side } \\
\text { (Downstream) }\end{array}$} & \multirow{3}{*}{ Overcurrent } & $\mathrm{I}$ & Coordinating with upstream stage I & $0.866 I_{\mathrm{f}(3)} / 2 / 1.1$ & $0 \mathrm{~s}$ \\
\hline & & II & Coordinating with next stage I & $1.2 \times 6 I_{\mathrm{e}}$ & $0.3 \mathrm{~s}$ \\
\hline & & III & Maximum load current & $1.3 n I_{\mathrm{e}}$ & $0.6 \mathrm{~s}$ \\
\hline & \multirow{2}{*}{$\begin{array}{l}\text { Zero-sequence } \\
\text { Current }\end{array}$} & $\mathrm{I}$ & Grounding resistance limit current & $I_{\mathrm{a}}$ & $0.3 \mathrm{~s}$ \\
\hline & & II & Line capacitive current & $I_{\mathrm{b}}$ & $0.6 \mathrm{~s}$ \\
\hline \multirow{4}{*}{$\begin{array}{l}\text { Collection } \\
\text { Cable }\end{array}$} & \multirow{2}{*}{ Overcurrent } & $\mathrm{I}$ & Step-up transformer inrush currents & $6 I_{\mathrm{e}}$ & $0 \mathrm{~s}$ \\
\hline & & II & Maximum load current & $1.3 I_{\mathrm{e}}$ & $0.3 \mathrm{~s}$ \\
\hline & \multirow{2}{*}{$\begin{array}{l}\text { Zero-sequence } \\
\text { Current }\end{array}$} & $\mathrm{I}$ & Grounding resistance limit current & $I_{\mathrm{a}}$ & $0 \mathrm{~s}$ \\
\hline & & II & Line capacitive current & $I_{\mathrm{b}}$ & $0.3 \mathrm{~s}$ \\
\hline \multicolumn{6}{|c|}{$\begin{array}{l}I_{\mathrm{f}(3)} \text { means the short-circuit current in case of a three-phase fault at the } 35 \mathrm{kV} \text { bus in a collection station. } \\
I_{\mathrm{e}} \text { is the current of a branch cable at the rated conditions. } \\
n \text { means the number of branches connected into a bus in a collection station. } \\
I_{\mathrm{a}} \text { and } I_{\mathrm{b}} \text { are the setting values. }\end{array}$} \\
\hline
\end{tabular}

\subsection{Simulation results}

To explain the problem aforementioned better, some simulations in case faults on the overhead line are conducted. The results in Fig. 6 and Fig. 7 are derived when the PV generation units operate at $0.6 \mathrm{pu}$ in unity $\mathrm{PF}$, In Fig. 6, the subscript down and up mean the downstream and the upstream. The phase differences of fault-phase currents are shown in Fig. 7.

In Fig. 6 and Fig. 7, an $A B$ to ground fault (ABG) occurs within the zone of the pilot relay on the overhead line. The during-fault currents from the PV system are symmetrical and the value increases not great much compared with the prefault one. The upstream current is about 20 times the downstream current. The prefault currents from the downstream and those from the upstream are in inverse phase. During the fault, $I_{\text {downA }}$ lags $I_{\text {sysA }}$ by $21^{\circ}$, while $I_{\text {downB }}$ leads $I_{\text {upB }}$ by $40^{\circ}$. Though there is a phase shift between the currents from two ends, the operating current of the pilot protection is almost equal to the braking current for faulty phases. Obviously, the ratio between the operating current and the braking current is close to one so that the sensitivity of the pilot element is reduced.

With the same fault condition but operating at $0.2 \mathrm{pu}$ in unity $\mathrm{PF}$, the upstream current is about 40 times the value of the downstream current during the fault. The ratio of the operating current and the braking current is 
closer to 1.

The fault-phase currents from the upstream are high enough to ensure the upstream overcurrent protection to pick up. However, the current of each phase from the downstream could not reach the zones of the downstream overcurrent protection.

As for the zero-sequence current protection, the upstream current in the zero-sequence circuit will be many times higher than the downstream capacitive current and the same problem exists. To avoid redundancy, this is not displayed in this paper.

In order to improve the existing protection configuration, a set of transmitting and receiving device could be installed along the protection of overhead lines. Once the upstream relay operates, the downstream relay will receive an operating signal from upstream and operate immediately. This method is simple but its drawback is that extra communication apparatuses will increase the cost.

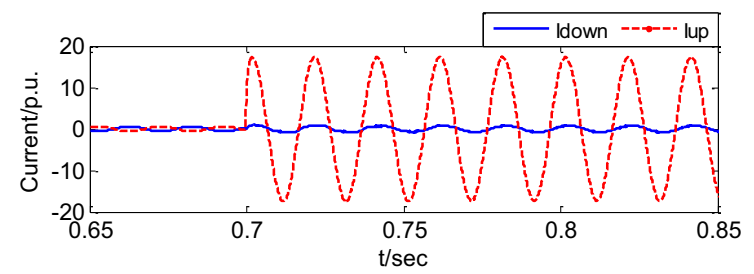

Figure 6. The fault-phase current from the upstream and downstream side under $\mathrm{ABG}$ with the operation of $0.6 \mathrm{pu}$ in unity PF

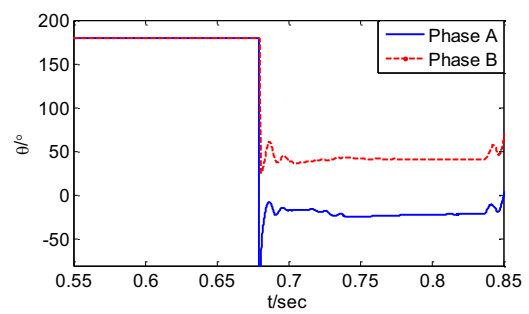

Figure 7. Phase difference between the downstream current and the upstream current of faulty phases.

\section{Conclusion}

The analysis of the fault currents recorded in a field test shows that the short-circuit currents supplied by the PV system increase not much and the postfault current level cannot be discriminated from the prefault one. Faults on the overhead line will not be detected by the overcurrent protection downstream. And the sensitivity of the pilot protection will be reduced for the same reason. This may result in the upstream protection operating prior to the downstream one with security risks. However, possible false trips of the overcurrent protections at adjacent lines can be eliminated, which is a significant problem in Wind Farms. The same problem exists for the zero-sequence current protection, as the zero-sequence circuit do not include PV generation units. The problem occurs when the pilot current protection fails, and this could be avoided via a simple method. The present protection configuration can response correctly to most requirements and situations and this protection scheme could be referred for PV power plants with similar topology.

\section{References}

1. A. Hooshyar , M.A. Azzouz, and E.F. El-Saadany, "Distance Protection of Lines Emanating from Full-Scale Converter-Interfaced Renewable Energy Power Plants-Part I: Problem Statement." IEEE Trans. Power Deliv., 30, 11 (2015)

2. M. Ding, Z.C. Xu, W.S. Wang, X.L. Wang, Y.T. Song and D.Z. Chen, "A review on China' s large-scale PV integration: Progress, challenges and recommendations," Renew Sustain Energy Rev, 53, 14 (2016)

3. A. Marinopoulos, F. Papandrea, M. Reza, S. Norrga, F. Spertino, and R. Napoli, "Grid integration aspects of large solar PV installations: LVRT capability and reactive power/voltage support requirements," Proc. IEEE Trondheim PowerTech, 8 (2011)

4. M. Mirhosseini, J. Pou, and V. Agelidis, "Single and two-stage inverter based grid-connected photovoltaic power plants with ride-through capability under grid faults," IEEE Trans. Sustain. Energy, 10 (2014)

5. M. Mirhosseini, J. Pou, and V. Agelidis, "Individual phase current Control with the capability to avoid overvoltage in grid-connected photovoltaic power plants under unbalanced voltage sags." IEEE Trans. Power Electron., 30, 6 (2015)

6. R. A. Walling, R. Saint, R. C. Dugan, J. Burke, and L. A. Kojovic, "Summary of distributed resources impact on power delivery systems," IEEE Trans. Power Del., 239 (2008)

7. Y. Lu, J. Du, X. Lin, and J. Ma, “An asymmetrical fault line selection based on I2 scalar product research in distribution system with DGs," Proc. IEEE PES Gen. Meet., 6 (2008)

8. J. Driesen and R. Belmans, "Distributed generation: Challenges and possible solutions," Proc. IEEE Power Eng. Soc. General Meeting, 8 (2006)

9. M. A. Haj-Ahmed and M. S. Illindala, "The Influence of Inverter-Based DGs and Their Controllers on Distribution Network Protection," IEEE Trans. on Industry Applications, 50, 10 (2014)

10. F. Coffele, C. Booth, and A. Dysko, "An adaptive overcurrent protection scheme for distribution networks," IEEE Trans. Power Del., 30, 8 (2015)

11. J. Rocabert, A. Luna, F. Blaabjerg and P. Rodriguez, "Control of power converters in AC microgrids." IEEE Trans. Power Deliv., 27 16(2012)

12. S.H. Sun, H.Q. Ben, Y.G. Li, L.Y. Wang and S. Yu, "Theory analysis of harmonic current generation and harmonic current extraction of three-phase grid-connected inverter." 9th International Conference on Power Electronics and ECCE Asia, 6 (2015)

13. E. Ebrahimi, J.S. Mohammad, and G.B. Gevork, "Control of three-phase inverter-based DG system during fault condition without changing protection coordination." Int J of Electr Power Energy Syst, 63 8 (2014)

14. China Electric Power Research Institute. GB/T 19964-2012. Technical requirements for connecting photovoltaic power station to power system. Beijing: Standards Press of China; (2013) 